\title{
MECANISMOS DE FORMAÇÃO DE EDEMAS
}

\author{
MECHANISMS OF EDEMA FORMATION
}

Eduardo Barbosa Coelho

Docente. Disciplina de Nefrologia. Departamento de Clínica Médica. Faculdade de Medicina de Ribeirão Preto - USP.

CorRespondênciA: Av Bandeirantes, 3900, CEP 14048-900 - Ribeirão Preto - SP - email: ebcoelho@fmrp.usp.br - Fone: 16-602-2543 / Fax: 16- 633-6695

COELHO EB. Mecanismos de formação de edemas. Medicina, Ribeirão Preto, 37: 189-198, jul./dez. 2004

RESUMO: Edema é definido como acúmulo de fluido no espaço intersticial. Nesta revisão, discutem-se os mecanismos formadores de edemas localizados e dos grandes edemas (generalizados), assim como aspectos semiológicos, empregados em seu diagnóstico diferencial. São detalhados os mecanismos patofisiológicos dos edemas cardíaco, cirrótico e renal (síndromes nefrítica e nefrótica) com destaque para as alterações dos mecanismos de controle do volume arterial efetivo.

UNITERMOS: Edema; fisiopatologia. Fibrose. Nefrite. Síndrome. Síndrome Nefrótica. Insuficiência Cardíaca.

\section{1- INTRODUÇÃO}

Edema é definido como acúmulo de líquido no espaço intersticial. Na prática clínica, nos deparamonos com pacientes com edemas de pequenas dimensões, localizados, por exemplo, em uma extremidade de um membro. Em outras situações, somos apresentados a pacientes com grandes edemas, envolvendo, inclusive, cavidades. Para que o edema ocorra, deve haver uma quebra dos mecanismos que controlam a distribuição do volume de líquido no espaço intersticial. Essa desregulação pode ser localizada e envolver apenas os fatores que influenciam o fluxo de fluido ao longo do leito capilar, ou, ainda, pode ser secundária a alterações dos mecanismos de controle do volume do compartimento extracelular e do líquido corporal total, o que, na maioria das vezes, ocasiona edema generalizado. A compreensão dos mecanismos formadores de edema é complexa e, em muitas situações, incompleta. Entretanto, o conhecimento dos mecanismos fisiopatológicos, envolvidos na formação do edema permite uma racionalização terapêutica na busca dos melhores resultados possíveis. Esta revisão pretende discutir os principais mecanismos locais, responsáveis pela formação do edema, ou seja, rever e discutir o equilíbrio capilar de Starling, assim como conhecer os mecanismos envolvidos na instalação e manutenção dos grandes edemas, levando à identificação dos mesmos através de conhecimentos semiológicos.

\section{2- ASPECTOS FISIOPATOLÓGICOS - EQUI- LÍBRIO DE STARLING}

Em 1896, Starling descreveu as forças fisiológicas que controlam o movimento de fluidos ao longo do leito capilar, e que, quando alteradas, podem gerar o edema ${ }^{(1)}$. Em resumo, o fluxo dos fluidos, no nível capilar, depende da permeabilidade da parede capilar, definida pela constante $K f$, e pela diferença entre as variações das pressão hidrostática ( $\square \mathrm{Pc}$ ) e da pressão oncótica ( $\square \square$ c) ao longo do leito capilar.

Assim: $\quad$ Fluxo $=K f .(\square \mathrm{Pc}-\square \square \mathrm{c})$ 
A Figura 1 esquematiza o equilíbrio de Starling no nível do leito capilar. Em condições fisiológicas, espera-se que a pressão hidrostática, na extremidade arteriolar do leito capilar, seja maior que a pressão oncótica do plasma. Esse gradiente de pressão faz com que haja fluxo de fluido do compartimento intravascular para o interstício. Ao longo do capilar, a pressão hidrostática se reduz de forma significativa. Em adição, a saída do fluido intravascular faz com que a concentração de proteínas intracapilares se eleve, o que acarretará um discreto aumento da pressão oncótica. Assim, somados esses fatores, ocorrerá inversão do gradiente de pressão na extremidade venosa da rede capilar, ou seja, a pressão oncótica tornar-seá maior que a pressão hidrostática. O eventual excesso de líquido no espaço intersticial será drenado através dos vasos linfáticos.

Perturbações nas variáveis que regem o equilíbrio de Starling poderão ocasionar edema. Caso ocorram em um território capilar restrito, haverá formação de edema localizado. Os grandes edemas envolvem, geralmente, alterações sistêmicas mais complexas, sendo ocasionados, na maioria das vezes, por pertur- bações nos mecanismos de controle do volume extracelular. Nesse caso, haverá aumento do volume extracelular e do peso corpóreo. O aparecimento de edema é conseqüência de alterações na homeostase do sódio e da água ${ }^{(2,3)}$. Como só acontece em Biologia e, portanto, também na patofisiologia das doenças, os processos (mórbidos) são multifatoriais, ou seja, vários fatores atuam simultânea e conjuntamente para desencadear um determinado quadro patológico. $\mathrm{O}$ edema não foge à regra. Assim, cada caso de edema resulta da composição de um ou vários fatores daqueles mostrados na Figura 1 e na 2. Na dependência de tais fatores, ficam caracterizados os edemas como: cardíaco, renal, cirrótico ou nutricional - grupados nesses nomes, porque, além das características patofisiológicas próprias de cada grupo, apresentam também etiologia específica, daí a denominação.

Na Figura 2, encontram-se resumidas as principais alças fisiológicas de controle do volume extracelular, que atuam no sentido da retenção de sódio. Apenas para não tornar a figura muito complexa, estão omitidas algumas alças natriuréticas, como o fator natriurético atrial (FAN), as prostaglandinas, as cininas

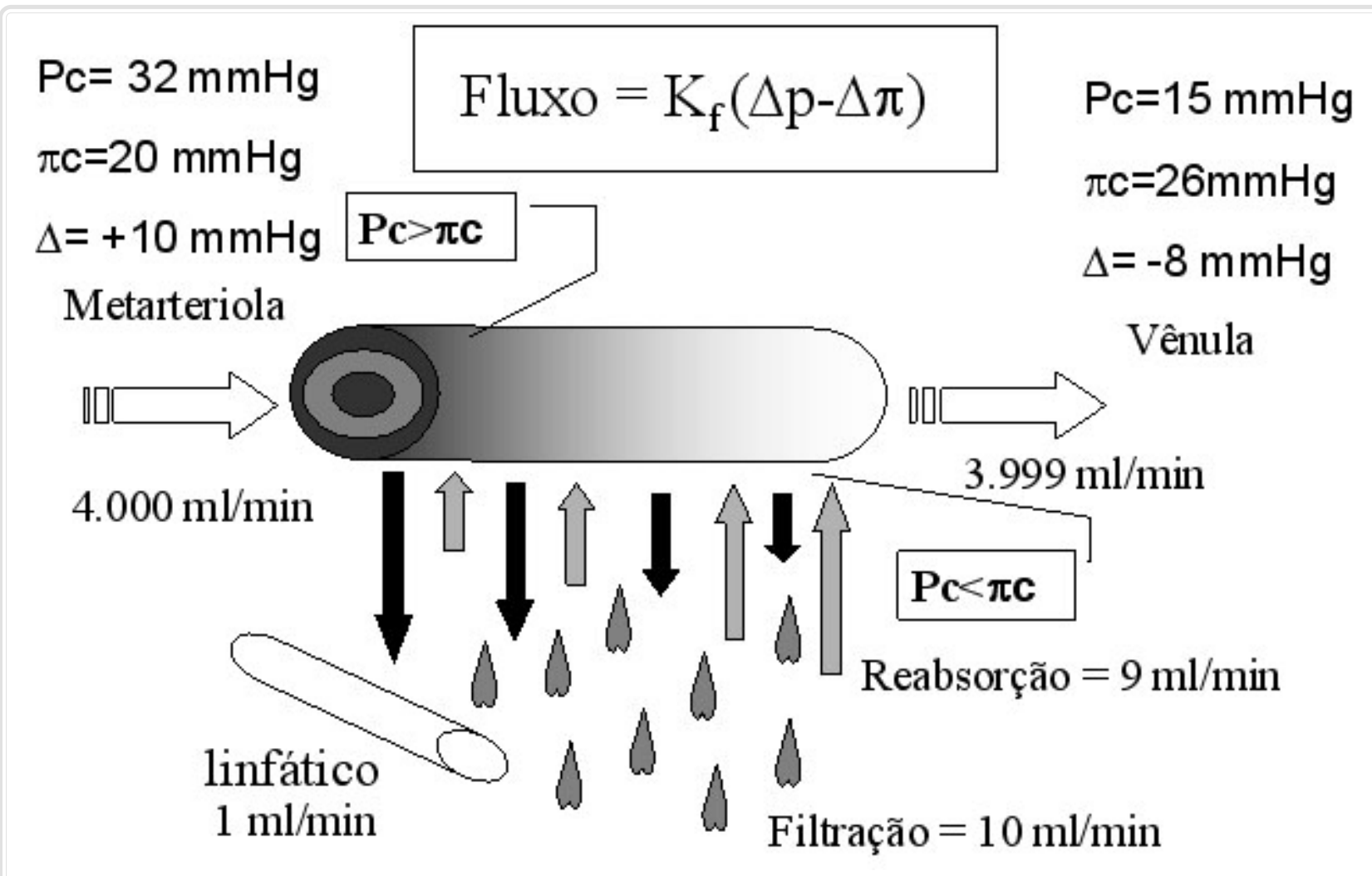

Figura 1- Forças que controlam o fluxo de fluído no leito capilar. Pc=pressão hidrostática capilar; $\mathbb{~} \mathrm{c}=$ pressão oncótica capilar; $K f=$ coeficiente de filtração; $\square$ e e $\square \square=$ diferença artériovenosa da pressão hidrostática e oncótica. 
e o óxido nítrico, assim como o hormônio antidiurético (HAD). Observe que os principais sistemas de regulação, ou seja, o sistema nervoso autônomo simpático (SNAS) e o sistema reninangiotensina-aldosterona (SRAA) atuam ou dependem do envolvimento renal. Os rins são, dessa forma, não só o principal efetor no balanço de água e sódio, mas, também, um importante sensor, levando ao SNC informações sobre o volume extracelular através das aferências nervosas. Em adição aos sensores de volume e pressão, localizados nas arteríolas aferentes, a mácula densa também é um importante sensor da concentração de sódio no interior dos túbulos renais e, em conjunto com o SNAS, controla a liberação de renina do aparelho justaglomerular renal. A Figura 2 introduz, ainda um importante conceito no entendimento da formação dos edemas generalizados. Trata-se do volume de sangue arterial efetivo (VSAE), um parâmetro de difícil mensuração, que representa o volume de sangue necessário para manter o retorno venoso, a perfusão tecidual e o débito cardíaco dentro dos valores normais. $\mathrm{O}$ VSAE depende do volume de sangue ejetado pelo coração (volume sistólico), que é diretamente influenciado pelo retorno venoso ao átrio direito (lei de Frank-
Starling), que, por sua vez, depende do tônus das grandes veias e, principalmente, do volume de sangue intravascular. A redução do VSAE ativará os mecanismos de controle de volume no sentido da retenção renal de água e sódio. Conforme detalharemos em seguida, as síndromes dos grandes edemas são acompanhadas de alterações do VSAE ou do seu principal órgão regulador, os rins.

\section{3- ASPECTOS SEMIOTÉCNICOS}

Uma história clínica e um exame físico cuidadoso são suficientes, na maioria dos casos, para o esclarecimento diagnóstico em pacientes com edema. $\mathrm{O}$ primeiro passo a ser dado visa à busca de pistas diagnósticas para a identificação de edemas localizados ou generalizados. As Tabelas I, II e III resumem os principais pontos a serem explorados para se atingir esse objetivo. Em adição, as Figuras 4 e 5 ilustram exemplos de edemas localizados. Entretanto, dois aspectos são passíveis de comentários mais detalhados. O primeiro relaciona-se à importância da aferição seqüencial do peso corporal. Edemas generalizados são acompanhados do aumento do peso e esse é um im-

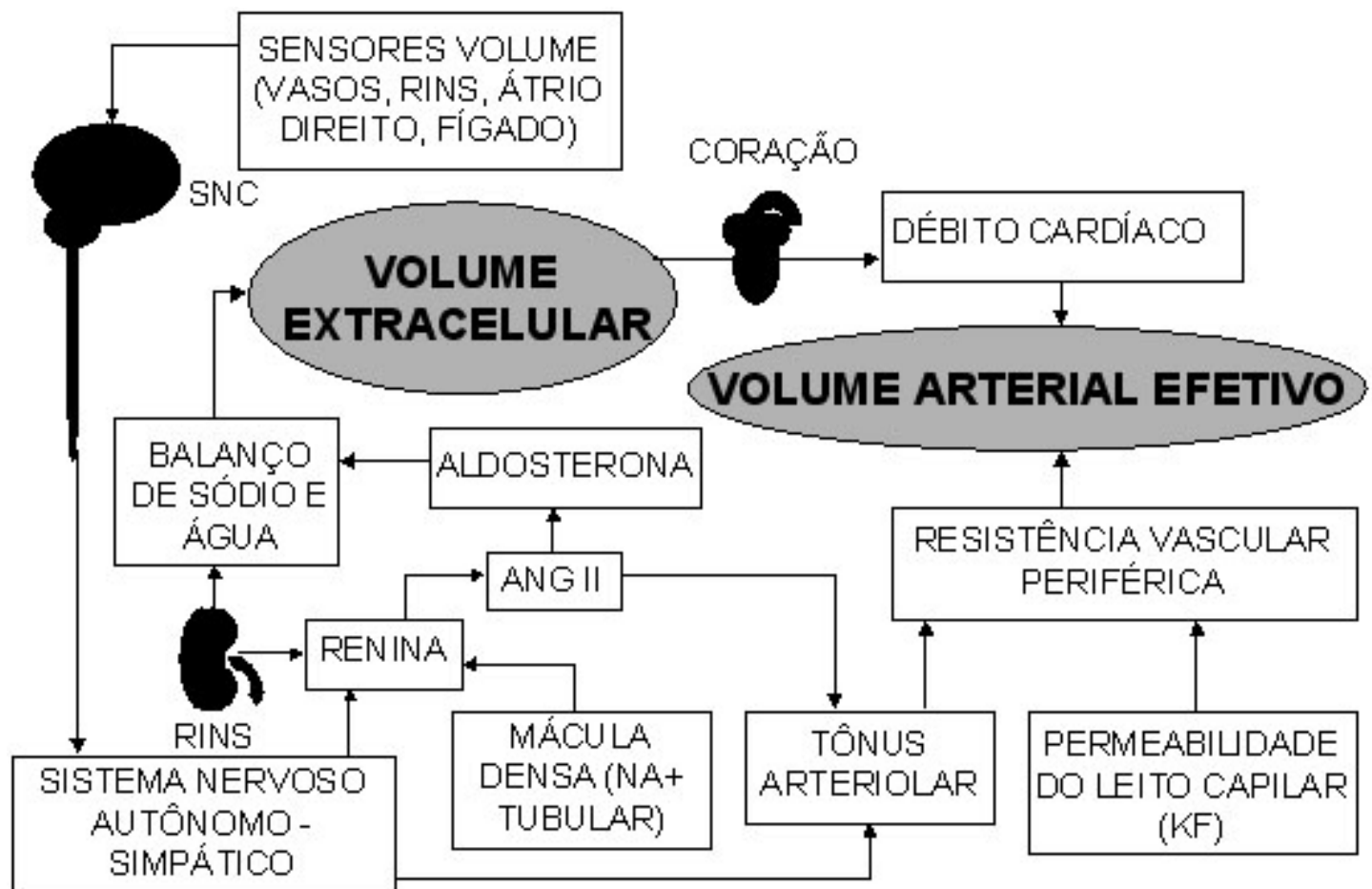

Figura 2 - Vias relacionadas com a retenção de sódio para o controle do volume arterial efetivo 
portante parâmetro para avaliação da eficácia terapêutica. Estima-se que sejam necessários cerca de 4 a $5 \%$ de aumento do peso corpóreo para que o edema seja clinicamente detectável. O segundo comentário refere-se ao sinal do cacifo ou de Godet (Figura 3). Esse sinal é realizado, comprimindo-se a região prétibial com o polegar por cerca de 10 seg e observando-se se há formação de depressão. A profundidade da depressão pode ser comparada com escala de cruzes, variando de $+\mathrm{a}++++$. Para efeito de compara- ção, a intensidade máxima (++++) é atribuída a edemas que formam depressões maiores ou iguais a uma polpa digital. Uma segunda informação pode ser obtida, observando-se o tempo necessário para o desaparecimento da depressão após a remoção da compressão digital. Caso a depressão desapareça em um tempo menor que $15 \mathrm{seg}$, suspeita-se de baixa pressão oncótica, ou seja, hipoalbuminemia. Tempos maiores que esse sugerem edema secundário ao aumento da pressão hidrostática (4).

Tabela I: Edemas Generalizados - Diagnóstico Diferencial.

\begin{tabular}{|c|c|c|c|}
\hline Etiologia & Mecanismo & Semiótica & Exames Complementares \\
\hline Síndrome Nefrótica & $\begin{array}{l}\text { Alta Ph, } \\
\text { Baixa } \square \text { c } \\
\text { (Leito Capilar) }\end{array}$ & $\begin{array}{l}\text { Urina Espumosa, } \\
\text { Edema Facial e Matutino, } \\
\text { Anasarca }\end{array}$ & $\begin{array}{l}\text { Proteinúria } \square 3,5 \mathrm{~g} / \mathrm{dia} \text {, } \\
\text { Hiperlipidemia } \\
\text { Hipoalbuminemia }\end{array}$ \\
\hline $\begin{array}{l}\text { Síndrome Nefrítica } \\
\text { IRA }\end{array}$ & $\begin{array}{l}\text { Alta } \mathrm{Ph} \\
\text { (Leito Capilar) }\end{array}$ & $\begin{array}{l}\text { Hipertensão Arterial, } \\
\text { Hematúria } \\
\text { Oliguria, } \\
\text { Náuseas }\end{array}$ & $\begin{array}{l}\text { Urina I (Hematúria, Cilindros) } \\
\text { Creatinina e Uréia Elevadas (Azotemia) } \\
\text { Eletrólitos }(\mathrm{K}+\square, \mathrm{Na}+\square)\end{array}$ \\
\hline $\begin{array}{l}\text { Insuficiência Cardíaca } \\
\text { Congestiva }\end{array}$ & $\begin{array}{l}\text { Pressão Venosa } \\
\text { Elevada } \\
\text { (Alta Ph) } \\
\text { Baixo VAE }\end{array}$ & $\begin{array}{l}\text { Dispnéia, } \\
\text { Estase Jugular } \\
\text { Hepatomegalia } \\
\text { Edema Vespertino }\end{array}$ & $\begin{array}{l}\text { Radiografia do Tórax } \\
\text { Ecocardiograma }\end{array}$ \\
\hline Cirrose Hepática & $\begin{array}{l}\text { Baixa } \square \mathrm{c} \\
\text { Alto } \mathrm{Kf} \\
\text { Alta } \mathrm{Ph} \\
\text { Baixo VSE }\end{array}$ & Vide Tabela V & $\begin{array}{l}\text { Tempo de Protrombina, Bilirrubinas, } \\
\text { Enzimas Hepáticas, Ultrasom } \\
\text { Abdominal, Albumina, Endoscopia }\end{array}$ \\
\hline
\end{tabular}

Tabela II: Edemas Localizados - Diagnóstico Diferencial.

\begin{tabular}{|l|l|l|l|l}
\hline Etiologia & Mecanismo & Semiótica & Testes e Conduta Terapêtica \\
\hline Erisipela (Inflamação) & $\begin{array}{l}\text { Alta Permeabilidade do } \\
\text { Leito capilar }\end{array}$ & $\begin{array}{l}\text { Calor, Rubor, Ardor, } \\
\text { Turgor }\end{array}$ & Antibióticos Analgésicos \\
\hline Trombose Venosa Profunda & $\begin{array}{l}\text { Pressão Venosa Elevada } \\
\text { (Alta Ph) }\end{array}$ & $\begin{array}{l}\text { Edema Assimétrico, } \\
\text { Circulação Colateral) }\end{array}$ & Anticoagulantes (Heparina) \\
\hline Linfedema & Obstrução Linfática & $\begin{array}{l}\text { Edema Assimétrico e } \\
\text { Duro. Gânglios }\end{array}$ & Causa Base \\
\hline
\end{tabular}

Tabela III: Edemas Localizados: Diagnóstico Diferencial.

\section{Etiologia}

Angioedema

Antagonistas Cálcio

\section{Mecanismo}

Alta Permeabilidade do Leito Capilar

Vasodilatação Arteriolar (Alta $\mathrm{Ph}$ )

\section{Semiótica}

Assimétrico, Frio e Indolor

Edema Simétrico, Indolor Tornozelos 

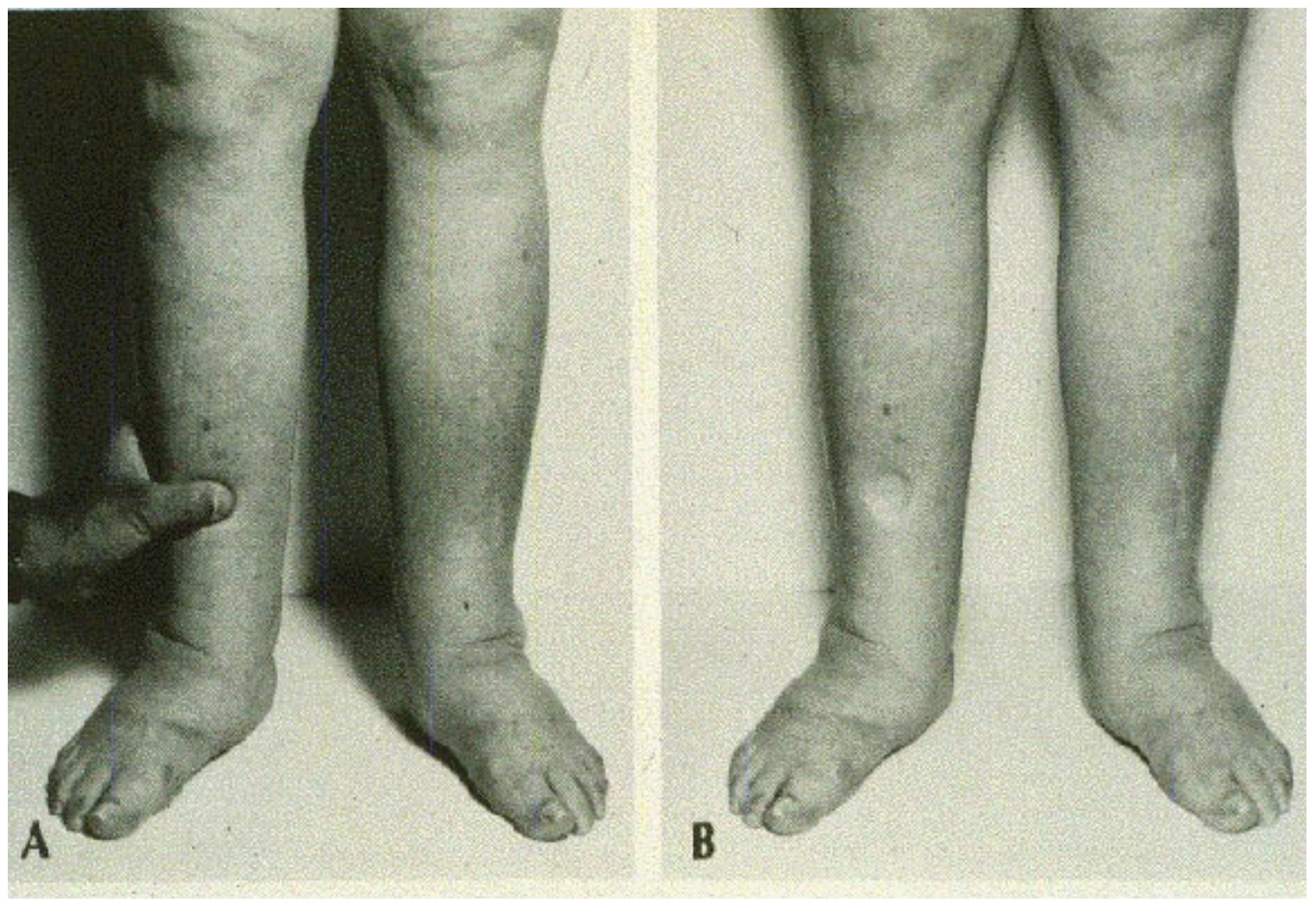

Figura 3: Sinal de Godet ou do cacifo. A- Modo de execução; B- presença do cacifo.

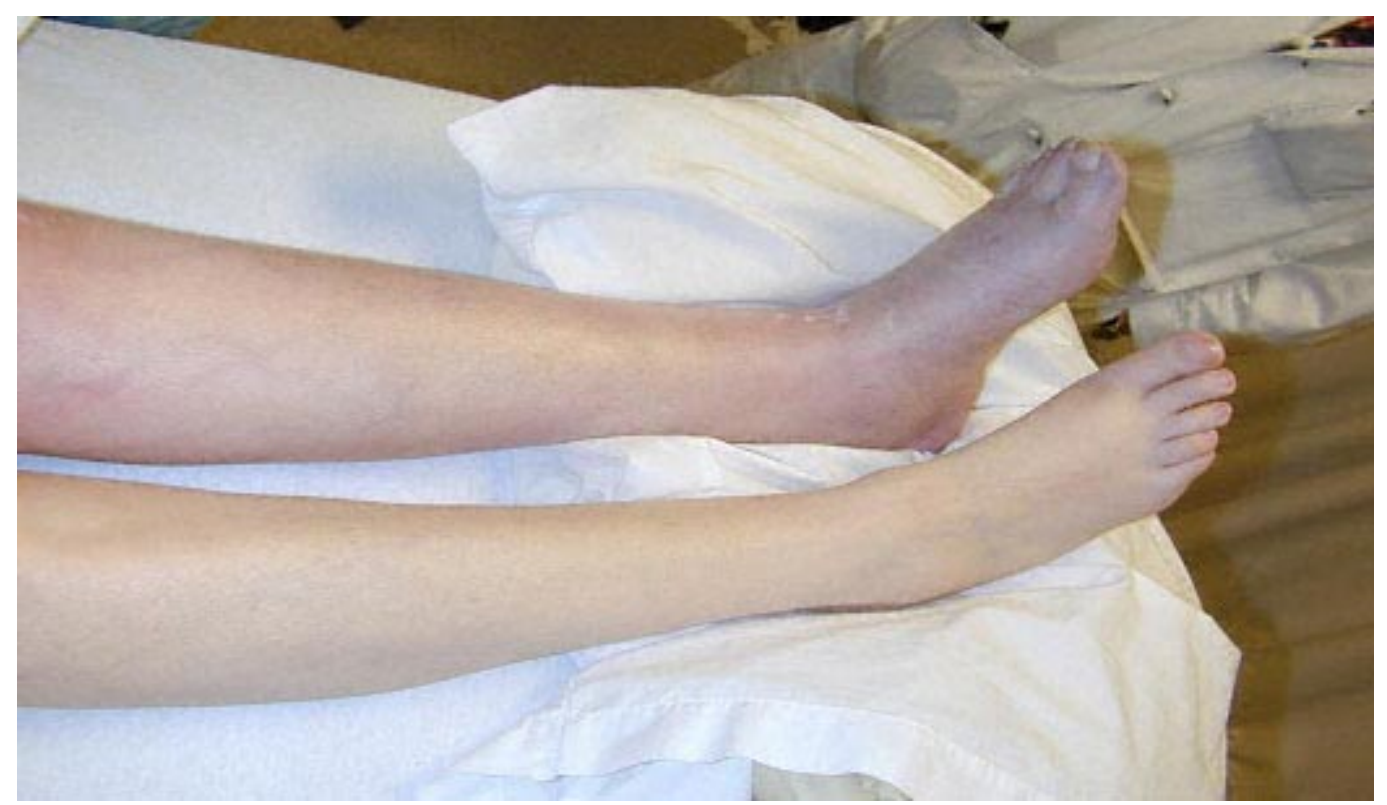

Figura 4: Edema localizado em trombose venosa, profunda, de membro inferior esquerdo. Note a assimetria do edema e a alteração da coloração da pele (cianose). 
(solutos) que será ainda mais reduzida após a maior reabsorção tubular desse íon. Assim, a pequena oferta distal de sódio permitirá a reabsorção quase total do $\mathrm{Na}^{+}$tubular no nefro distal. Cai a excreção renal de sódio e acontece, desse modo, retenção de $\mathrm{Na}^{+}$(e água, de equilíbrio osmótica). Essencialmente, é um rim com capacidade muito pequena de excreção de $\mathrm{Na}^{+}$. Se fizermos restrição dietética de $\mathrm{NaCl}$ (rigorosa), pode não se formar edema - pois equilibrar-se-ia a ingestão com a baixa excreção, sem retenção. Mas se o consumo de sódio for liberal, ocorrerá retenção de $\mathrm{Na}^{+} \mathrm{e}$ expansão do volume do extracelular(VEC), como mostra a Figura 6. Nessas condições, haverá edema e hipertensão arterial. Nos casos de insuficiência renal aguda (necrose tubular aguda) pode haver ou não a formação de edema. Essa doença cursa com destruição das células tubulares e pode evoluir desde oligoanúria até poliúria. Assim, a presença de edema dependerá da associação entre a redução da $\mathrm{TFG}$, a redução na carga excretada de sódio e o aporte de sódio na dieta. Cabe lembrar que a presença de IRA é comum em pacientes críticos, sujeitos a grande aporte de líquidos por infusão parenteral, ricos em sódio, fator que pode levar a expansão do volume extracelular, aumento da pressão hidrostática capilar e edema ${ }^{(5)}$.

\section{$\mathrm{B}$}

Figura 5: Exemplos de edema localizado: A- Angioedema em lábio superior; B - Erisipela em membro inferior (note o eritema, indicando inflamação).

\section{4- SÍNDROMES DOS GRANDES EDEMAS}

\section{4-1 Edema Renal}

\section{Edema Nefrítico}

Nas síndromes nefríticas agudas, das glomerulonefrites agudas, por exemplo, que se manifestam com edema, hematúria, hipertensão - sem proteinúria importante (acima de 3,5 g/dia) - a causa fundamental do edema é a redução da taxa de filtração glomerular (TFG). Essa queda da filtração pode ser discreta em alguns pacientes (com creatinina sérica normal), mas pode ser mais grave em outros, sendo que alguns ficam até anúricos (necessitando diálise). O edema é tão mais grave quanto maior for a redução da TFG, pois, como conseqüência desta, ocorrerá uma diminuição muito acentuada da carga filtrada de sódio

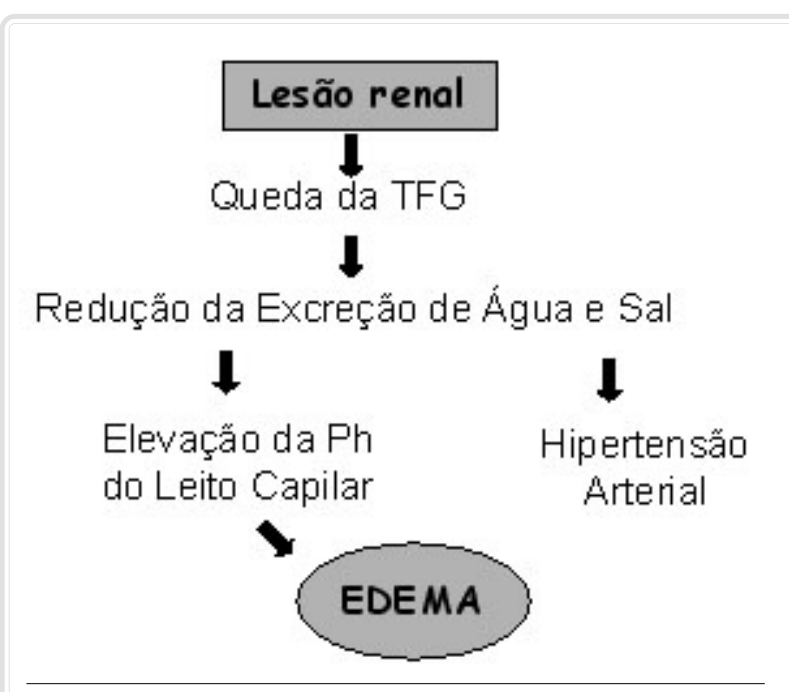

Figura 6: Mecanismos formadores de edema na Síndrome Nefrítica e na Insuficiência Renal Aguda.

\section{Edema Nefrótico}

Sempre que uma doença renal tiver a presença de lesões específicas da membrana basal glomerular e/ou dos pedicelos das células epiteliais glomerulares, haverá um aumento da permeabilidade glomerular às macromoléculas. Nessas condições, as proteínas 
plasmáticas são filtradas em grandes quantidades e a perda urinária (proteinúria) ultrapassa $3,5 \mathrm{~g} / 24 \mathrm{~h}$. Clinicamente, manifesta-se por urina espumosa (proteinúria) e edemas. Esse é um quadro que pode estar presente nas manifestações de várias doenças, portanto é chamado de Síndrome Nefrótica. O edema reflete a redução na pressão oncótica do plasma, o que irá acarretar uma menor reabsorção do fluido intersticial, na extremidade venosa do leito capilar. A Figura 7 mostra, esquematicamente, as alterações presentes na síndrome nefrótica, responsáveis pelo edema. A hipoproteinemia, resultante da perda urinária de proteínas, é agravada pelo catabolismo aumentado da albumina, que acontece na síndrome nefrótica. A redução da pressão oncótica do plasma, resultante da hipoproteinemia, por si só, leva ao aparecimento de edema. Além disso, pode provocar contração do volume intravascular, que pode acarretar redução do débito cardíaco (redução da pré-carga) e conseqüente redução da perfusão renal. Esta, por sua vez, leva à ativação do SRAA, reduzindo a excreção renal de sódio. A queda da pressão arterial ou do volume plasmático pode, ainda, estimular a liberação de hormônio antidiurético, que irá provocar retenção de água e hiponatremia. Nessas condições, haverá maior reabsorção de $\mathrm{Na}^{+}$e de água pelos túbulos renais, com retenção de sódio e água. Quando houver maior atividade antidiurética, poderá ocorrer retenção de água (livre de solutos), que promoverá diluição do extracelular, causando hiponatremia. Esse fluido retido repre- senta um efeito diluidor das proteínas plasmáticas, agravando a redução da pressão oncótica do plasma e reciclando o estímulo à formação de edema.

Clinicamente, o edema renal caracteriza-se pela localização facial, particularmente com a presença de edema palpebral - é um edema matinal, que tende a dissipar-se com o correr do dia - além do inchaço de membros inferiores, que (ao contrário) se exacerba com o passar das horas, constituindo um edema vespertino. Pacientes nefróticos com albumina plasmática muito baixa podem apresentar edema generalizado, intenso e extenso (anasarca), inclusive com derrames cavitários (serosites: ascite, derrames pleural e/ ou pericárdico).

\section{2- Edema Cardíaco}

Fundamentalmente, o que leva à formação desse edema é a queda do débito cardíaco, em conseqüência da falência do miocárdio. Como resultado, eleva-se a pressão venosa sistêmica ao mesmo tempo em que se reduz o volume arterial efetivo de sangue (VAES). O volume de sangue, que banha os átrios cardíacos, o ventrículo esquerdo (VE), o arco aórtico, o seio carotídeo e a arteríola aferente renal, é crítico para o controle da volemia, pois esses são segmentos providos de receptores de volume e pressorreceptores que acusam um maior ou menor enchimento do lado arterial da circulação. Desse modo, fala-se em repleção vascular, overfilling, ou depleção vascular arterial, underfilling $^{(6)}$. Assim, neste texto, quando se fala em redução do volume arterial efetivo de sangue (VAES), entende-se um enchimento deficiente do leito vascular arterial; expansão do VAES corresponderá a um enchimento supérfluo do leito cardiovascular arterial.

A Figura 8 mostra Retenção de Sódio e Água Elevação da Ph no Leito Capilar

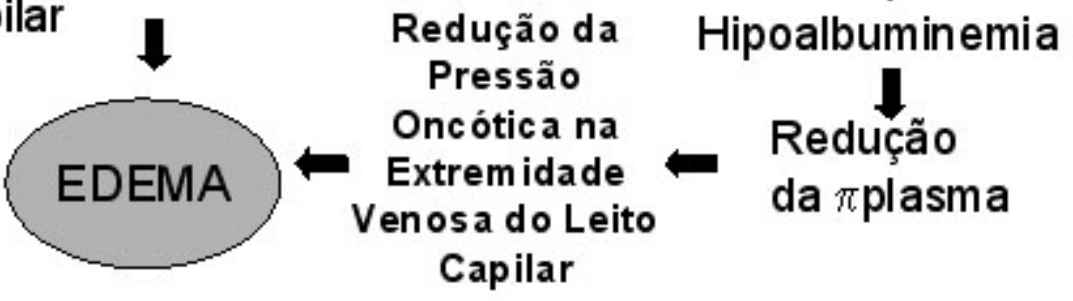

Figura 7: Mecanismos formadores de edema na Síndrome Nefrótica. Proteinúria

Alteração da Membrana de Filtração

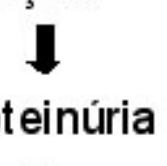

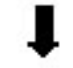

inemia

Redução

da $\pi$ plasma 
vascular na extremidade venosa do capilar, fica dificultado o retorno do líquido intersticial para o capilar, e água acumulase no interstício. Essa redistribuição do fluido extracelular concorre para a formação de edemas. A figura mostra, ainda, que outra conseqüência da queda no DC é a diminuição do VAES, ou seja, ocorrerá um enchimento deficiente do leito vascular arterial, com sensibilização de volumerreceptores e/ou pressorreceptores (Figuras 2 e 8). Essas figuras, apesar de complexas no seu aspecto (devido ao caráter multifatorial da patofisiologia do edema), ajudam a entender a interrelação existente entre os vários fatores envolvidos no mecanismo de formação dos edemas. A Figura 2 mostra a importante participação do sistema reninangiotensinaldosterona, levando à retenção renal de sódio. Além disso, a retenção de água, desacompanhada de soluto (água-livre) - por ação do HAD - pode levar à diluição do sódio plasmático (hiponatremia).

Clinicamente, é um edema gravitário por excelência, por causa da pressão venosa elevada nas extremidades e, portanto, acentua-se com a ortostase, no correr do dia (edema vespertino). Apesar da patofisiologia complexa, o reconhecimento da insuficiência cardíaca é relativamente simples devido à pletora de achados físicos e a sua evolução clínica. Assim, em um paciente com edema generalizado, o diagnóstico de insuficiência cardíaca é realizado na presença de história de dispnéia progressiva, que se inicia aos grandes esforços e culmina com ortopnéia; a presença de episódios de dispnéia paroxística noturna; as queixas de nictúria, hemoptise, tosse ou cianose; os antecedentes pessoais de doenças cardíacas (Chagas, doença isquêmica do miocárdio, miocardiopatias, hipertensão arterial e febre reumática entre muitas outras) e aos achados do exame físico (taquicardia com ritmo de galope, $3^{\circ}$ bulha, desvio do ictus cordis, estase jugular, estertores pulmonares crepitantes, derrame pleural e hepatomegalia).

\section{3- Edema Cirrótico}

Assim como comentado para a insuficiência cardíaca congestiva, a cirrose hepática também será acompanhada de uma série de achados clínicos que facilitam seu diagnóstico diferencial (Tabela IV). O processo cirrótico - resposta hepática a vários tipos de agressão que leva à fibrose e regeneração nodular do figado - afeta a função hepática em conseqüência do que descrevemos a seguir:

a) Alterações do funcionamento dos hepatócitos por causa das lesões celulares (necrose, proliferação), comprometendo, assim, a síntese de albumina.

b) Destruição da arquitetura lobular, canalicular e vascular, levando a distorções estruturais, que dificultam o livre fluxo de sangue e linfa nos sinusóides hepáticos - resultado disto é o aumento da pressão no território venoso (portal) e linfático (intra-hepático), que se conhece por hipertensão portal. Essa dificuldade de trânsito venoso através do fígado faz com que o sangue busque vias alternativas de tráfego, forçando o aparecimento de circulação colateral venosa, que promoverá um aumento da capacitância (venosa) esplâncnica, acarretando "aprisionamento" de sangue no território mesentérico. Esse sangue, seqüestrado no leito venoso "ampliado", irá prejudicar o enchimento vascular arterial underfilling, causando redução do volume efe- 
tivo de sangue com todas as conseqüências mostradas na Figura 2. Além disso, como ilustra a Figura 9, a hipoalbuminemia provocada pela deficiente síntese de albumina reduz a pressão oncótica do plasma e concorre para a formação do edema.

c) Formação de shunts arteriovenosos. A insuficiência hepática é acompanhada de um tônus vascular, deslocado para uma condição de relaxamento devido à redução do metabolismo de várias substâncias vasodilatadoras e ao aumento da produção de óxido nítrico. Assim, com a redução da resistência

Tabela IV: Principais achados clínicos em pacientes cirróticos.

Icterícia

Eritema Palmar

Encefalopatia Hepática

Hálito Hepático

Equimoses

Hematêmese/Melena

Esplenomegalia

Aranhas Vasculares (Spiders)

Hipotrofia Muscular

Alopecia, Ginecomastia e Atrofia Testicular (Homens)

Ascite

Circulação Colateral ("Cabeça de Medusa")

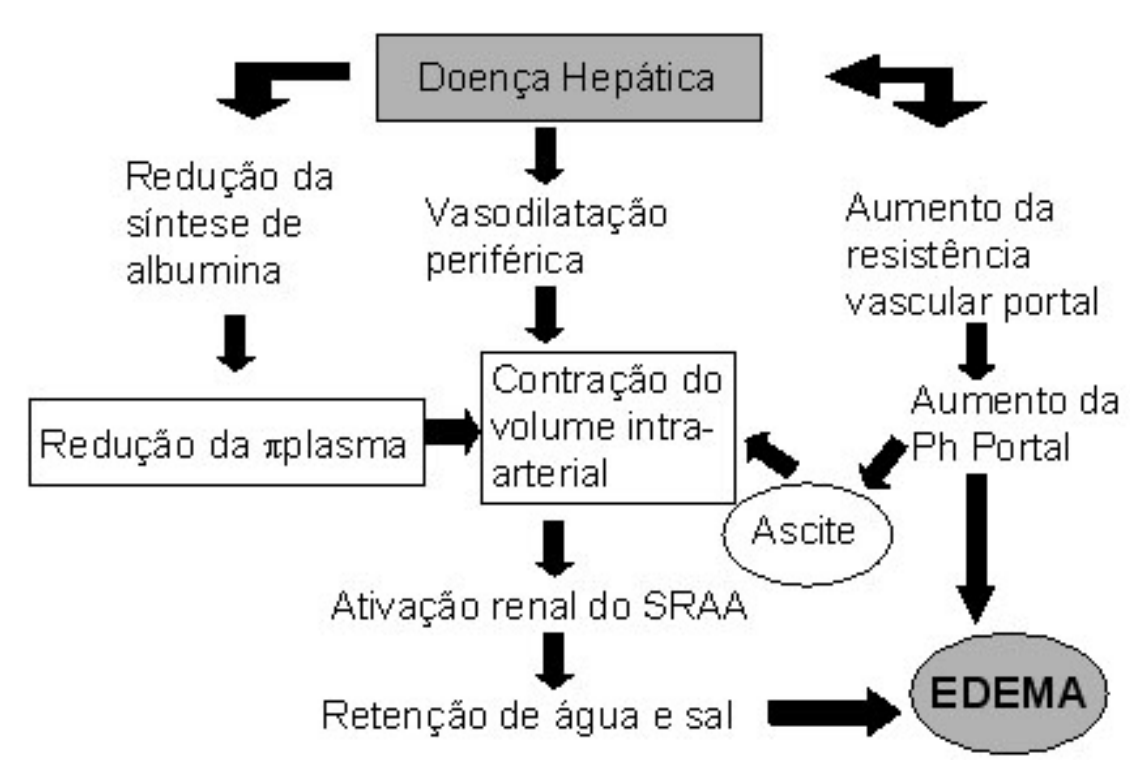

Figura 9: Mecanismos formadores de edema na Cirrose Hepática vascular periférica, há redução do VAES e ativação dos mecanismos de controle de volume extracelular (Figura 2) no sentido de retenção renal de água e sódio. Nesse sentido, são sólidas as evidências que mostram uma hiperatividade simpática e a ativação do SRAA, com conseqüente hiperaldosteronismo secundário, em pacientes cirróticos com $\operatorname{ascite}^{(7)}$

A existência de hipertensão portal torna o território esplâncnico mais vulnerável na presença de hipoalbuminemia, daí a ocorrência de transudação líquida para a cavidade peritonial, formando ascite com maior exuberância nos pacientes cirróticos - que é uma das características clínicas desse tipo de edema.

\section{5- CONCLUSÕES}

Essencialmente, a análise dos mecanismos formadores de edema é um estudo da regulação dos volumes líquidos do corpo e de seu controle pela excreção renal de $\mathrm{Na}^{+}$(e água) ${ }^{(7)}$. Assim, necessariamente, a patofisiologia dos edemas é complexa e multifatorial, como já foi dito. É fundamental que o médico conheça bem esses mecanismos para saber atuar adequadamente no tratamento dos vários tipos de edema, em que o único ponto comum é o uso de diuréticos ${ }^{(8)}$. Fogem a essa regra duas doenças não abordadas nessa revisão, o hipotireoidismo e a desnutrição protéica conhecida como Kuashiorkor. No hipotiroidismo há a formação de um edema duro, denominado de mixedema, secundário as alterações das glicosaminaglicanas do compartimento intersticial. Pacientes com hipotireoidismo, apresentam uma gama de sinais e sintomas sistêmicos, que possibilitam o diagnóstico diferencial. O tratamento, nesse caso, deverá ser feito com a reposição dos hormônios tireoideanos. A desnutrição protéica causa edema por hipoalbuminemia e vem acompanhada de uma série de outros sinais e sintomas, incluindo alteração da coloração dos cabelos, déficit de crescimento e associação com outras deficiências de vitaminas e oligoelementos 
com quadro clínico variável. O tratamento - uma nutrição adequada - ultrapassa as barreiras da Medicina e, infelizmente, parece ser de difícil resolução.

Se o estudo dos edemas constitui-se num exercício de fisiologia da excreção renal de $\mathrm{Na}^{+}$e da regulação do volume dos líquidos do corpo, o estudo das de- sidratações é também um exercício em fisiologia, agora da regulação da concentração osmótica do extracelular, com menor participação da regulação do volume. Desidratações e edemas estão entre as manifestações mais freqüentes dos desequilíbrios hidroeletrolíticos e são, portanto, de grande importância clínica.

COELHO EB. Mechanisms of edema formation. Medicina, Ribeirão Preto, 37: 189-198, july/dec. 2004.

ABSTRACT: Edema is defined as liquid accumulation in the interstitial space. In this review, the mechanisms of localized and generalized edema formation were discussed as well as semiologic aspects used in approach to its differential diagnosis. The pathophysiologic mechanisms of the cardiac, cirrhotic and renal (nephritic and nephrotic syndromes) edemas were detailed highlighting the alterations of the mechanisms of control of the effective arterial volume.

UNITERMS: Edema; physiopathology. Fibrosis. Nephritis. Syndrome. Nephrotic Syndrome. Heart Failure.

\section{REFERÊNCIAS BIBLIOGRÁFICAS}

1 - STARLING, EH. Physiologic forces involved in the causation of dropsy. Lancet 1: 1267-1270, 1896.

2 - BERNARD, C. Leçons sur les phénoménes de la vie, commun aux animaux et aux végétaux. Bailliére, J B et Fils, Paris, 1885.

3 - CANNON, W B. The wisdom of the body. New York, Norton, p.37-40, p.77-97, 1939.

4 - DISKIN CJ; STOKES TJS; DANSBY LM; CARTER TB; RADCLIFF L \& THOMAS SG. Towards an understanding of oedema. BMJ 318: 1610-1613, 1999.
5 - COSTA JAC; VIEIRA NETO OM; RAMOS FILHO R; COELHO EB; DOMINGUEZ GCS \& COIMBRA TM. Distúrbios do equilíbrio hidroeletrolítico e insuficiência renal aguda. Medicina, Ribeirão Preto 24: 452-457 1992.

6 - SCHREIER, RW. Body fluid volume regulation in health and disease: A unifying hypothesis. Ann Intern Med 113:155159,1990 .

7 - DUDLEY FJ. Pathophysiology of ascites formation. Gastroenterol Clin North Am 21: 215-235,1992.

8 - FURTADO MR. Mecanismos de formação de edemas. Medicina, Ribeirão Preto 27: 49-55, 1994. 